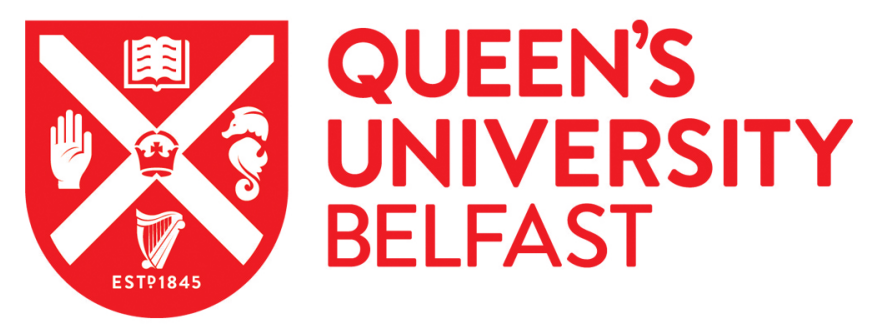

\title{
Exploring high-achieving sixth grade students' erroneous answers and misconceptions on the angle concept
}

\author{
Bütüner, S. Ö., \& Filiz, M. (2016). Exploring high-achieving sixth grade students' erroneous answers and \\ misconceptions on the angle concept. International Journal of Mathematical Education in Science and \\ Technology. https://doi.org/10.1080/0020739X.2016.1256444
}

Published in:

International Journal of Mathematical Education in Science and Technology

\section{Document Version:}

Peer reviewed version

Queen's University Belfast - Research Portal:

Link to publication record in Queen's University Belfast Research Portal

\section{Publisher rights}

(C) 2016 Informa UK Limited, trading as Taylor \& Francis Group

This is an Accepted Manuscript of an article published by Taylor \& Francis in International Journal of Mathematical Education in Science and Technology on 23 Nov 2016, available online: http://www.tandfonline.com/doi/full/10.1080/0020739X.2016.1256444

\section{General rights}

Copyright for the publications made accessible via the Queen's University Belfast Research Portal is retained by the author(s) and / or other copyright owners and it is a condition of accessing these publications that users recognise and abide by the legal requirements associated with these rights.

Take down policy

The Research Portal is Queen's institutional repository that provides access to Queen's research output. Every effort has been made to ensure that content in the Research Portal does not infringe any person's rights, or applicable UK laws. If you discover content in the Research Portal that you believe breaches copyright or violates any law, please contact openaccess@qub.ac.uk. 


\title{
Exploring high-achieving sixth grade students' erroneous answers and misconceptions on the angle concept
}

\author{
Suphi Önder Bütüner ${ }^{\mathrm{a}}$ and Mehmet Filiz ${ }^{\mathrm{b}}$
}

\begin{abstract}
The aim of this research was to investigate high achievers' erroneous answers and misconceptions on the angle concept. The participants consisted of 233 grade 6 students drawn from eight classes in two well-established elementary schools of Trabzon, Turkey. All participants were considered to be current achievers in mathematics, graded 4 or 5 out of 5 , and selected via a purposive sampling method. Data were collected through six questions reflecting the learning competencies set out in the grade 6 curriculum in Turkey and the findings of previous studies that aimed to identify students' misconceptions of the angle concept. This questionnaire was then applied over a 40 minute period in each class. The findings were analyzed by two researchers whose inter-rater agreement was computed as 0.97 , or almost perfect. Thereafter, coding discrepancies were resolved, and consensus was established. We found that although the participants in this study were high achievers, they still held several misconceptions on the angle concept such as recognizing a straight angle or a right angle in different orientations. We also show how some of these misconceptions could have arisen due to the definitions or representations used in the textbook, and offer suggestions concerning their content in the future.
\end{abstract}

Keywords: the angle concept; misconception; erroneous answer; high achievers

\section{Introduction}

Piaget [1] claimed that children use schemas to understand the world and whenever they confront new knowledge, this new knowledge is either ignored or integrated into their existing schemas. This knowledge integration can result in meaningful learning [2] unless the prior schemas consisted of incomplete understandings and misconceptions which are common inaccurate beliefs about a concept or a process. In other words, if students hold misconceptions about a concept, they are less likely to comprehend a new concept which is associated with the previous one [3]. For instance, primary school students may hold misconceptions on the equals sign and negative signs in arithmetic $[4,5]$. These misconceptions could also be an obstacle for high school students while solving two-step equations in algebra. Booth and Koedinger [6] randomly divided 49 high school students into two groups. While one of these groups took a test for assessing their conceptual knowledge of algebra, the other took another test for assessing their procedural knowledge of algebra. After these tests, students were tutored with guided procedural practice solving two-step equations, provided instantaneous feedback on any errors, and could ask the Tutor for hints if they were unsure of what to do. Thereafter, post-tests were performed. In this study, they found that high school students held misconceptions about the equals sign and negative signs. They also found that those with these misconceptions struggled to learn from instruction on how to solve equations. As illustrated in this example, misconceptions were stable elements of learners' schemas and resistant barriers to learn new concepts despite instruction.

Misconceptions in geometry can arise for several reasons. To begin with, students over generalize specific rules about geometric expressions [7-9]. Moreover, geometric concepts are mostly learned by rote [7,8]. Also, they cannot fully comprehend concepts $[7,8]$. Finally, students may only learn one of the dual meanings of a concept such as the angle concept [10-15].

\subsection{Dual meaning of the angle concept}

The definitions of the angle concept can be classified into two categories as static and dynamic definitions based on the physical properties of the angles. Static definition refers to an intersection of two rays at the same end point looking like the opening of a pair of scissors [16].

This definition relies on the Euclidean approach where the angle is defined by a non-collinear pair of oblique lines and is placed into one plane without orientation through $0^{\circ}$ and $180^{\circ}$ [17]. On the other hand, the dynamic definition specifies the angle as a rotation referring to change in direction [18]. In other words, the amount of turn needed to carry one of the angle's arm over the other one without moving out the plane [19]. Since the static and dynamic of

\footnotetext{
${ }^{\text {a }}$ Department of Elementary Mathematics Education, Faculty of Education, Bozok University, Yozgat, Turkey;

${ }^{\mathrm{b}}$ Centre for Effective Education, School of Social Sciences, Education and Social Work, Queen's University

Q1 Belfast, Belfast, Northern Ireland, UK
} 
definitions represent two diverse situations and have unique limitations [10], the union of these definitions cannot be determined. Due to this issue, students may harbour some misconceptions on the angle concept.

\subsection{Elementary school students' misconceptions on the angle concept}

Studies have shown that students often have misconceptions about the concept angle. First of all, they might assume that the intersection of two arcs or the intersection of a ray with an arc is an angle [12]. In addition, students tend to relate the size of the angles with the size of their arms. They may hold that the longer the arms the angle has, the larger the angle is [12,20-23]. Additionally, students may think that the size of the angle is related to the size of the arc between its arms [22,24]. Moreover, students may assume that the size of an angle is associated with the area enclosed by an arc and its arms $[13,15,25]$. Some students cannot recognize the $180^{\circ}$ angle $[12,26,27]$. Furthermore, students can have difficulties in recognizing a right angle in different orientations [28,29]. Students have also had difficulties in adapting the angle concept to real life situations. For instance, some students use perpendicular lines instead of oblique lines for identifying blind spots behind obstacles [20,24,30].

The number of studies aiming to investigate the aforementioned misconceptions on the angle concept among Turkish elementary school students is limited. In one study, Biber et al. [7] investigated learning levels, mistakes, and misconceptions of eighth grade students on the angle concept. They asked 30 students to answer four openended questions, and their responses were first classified as correct and incorrect. Thereafter, the students reasoning for incorrect answers were divided into three broad categories. First, students considered the physical appearances of geometric figures alone without paying attention to their geometric properties. Second, they identified a few geometric properties of figures, yet they could not associate these properties with other knowledge required for the solution. Finally, they generalized a property that was valid for only a specific condition over different situations. The results of this study demonstrated that some Turkish students did not fully grasp the concept of parallelism on the angle concept. Although Biber et al. [7] identified students' errors in relation to the concept of parallelism, their study did not examine students' misconceptions related to the size and orientation of angles.

\subsection{The potential role of mathematics textbooks in supporting misconceptions}

Mathematics textbooks are primary sources for both teachers and students because while mathematics textbooks assist teachers to prepare classes and/or exam questions and to teach, students may use them to study and to solve homework questions [31]. Thus, the content of mathematics textbooks is remarkably crucial. On the other hand, Kajander and Lovric [31] found that reader-friendly language, incorrect generalizations, oversimplifications, illustrations and diagrams in mathematics textbooks may lead to misconceptions. Likewise, Markowsky [32] investigated that many high school geometry textbooks consisted of incorrect statements about the golden ratio. Similarly, Luneta [33] claimed that even though there are two squares in Figure 1, many students would only classify the shape on the right as a square because the shape on the left is the prototype of a rhombus in mathematics textbooks.
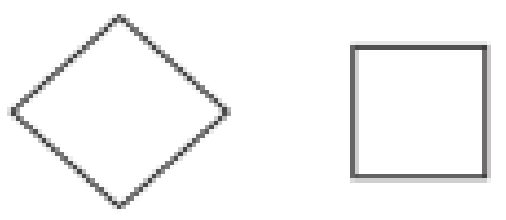

Figure 1. Two squares in different orientations

In the same vein, some of the aforementioned misconceptions on the angle concept could be induced by the definitions, explanations, representations or examples of the angle concept given in mathematics textbooks. For instance, if a static definition of the angle concept was only provided, students could theorize that the size of angles was associated with the space between their arms $[13,15,25]$. Another example would be that students might always expect angles to have one arm being extended horizontally because of the representations of angles in their textbooks [34]. Therefore, investigating their textbook is crucial for understanding how students develop some of these misconceptions. Additionally, exploring how the angle concept was represented in the grade 6 mathematics textbook can provide ample evidence for the mathematics teachers' practices of teaching the angle concept, because the majority of Turkish mathematics teachers tend to primarily use the mathematics textbook for lesson preparations and teaching practices [35-38]. 


\subsection{The primary source for lesson planning: the grade 6 mathematics textbook of Turkey}

The chapter of the grade 6 mathematics textbook of Turkey [39] on the angle concept begins with a picture of house roof followed by indicating that the size of roof slopes varies based on the weather conditions in Turkey. Thereafter, a static definition of the angle concept is given (see Figure 2(a)) followed by the following representation of an angle and how it is labeled as shown in Figure 2(b).

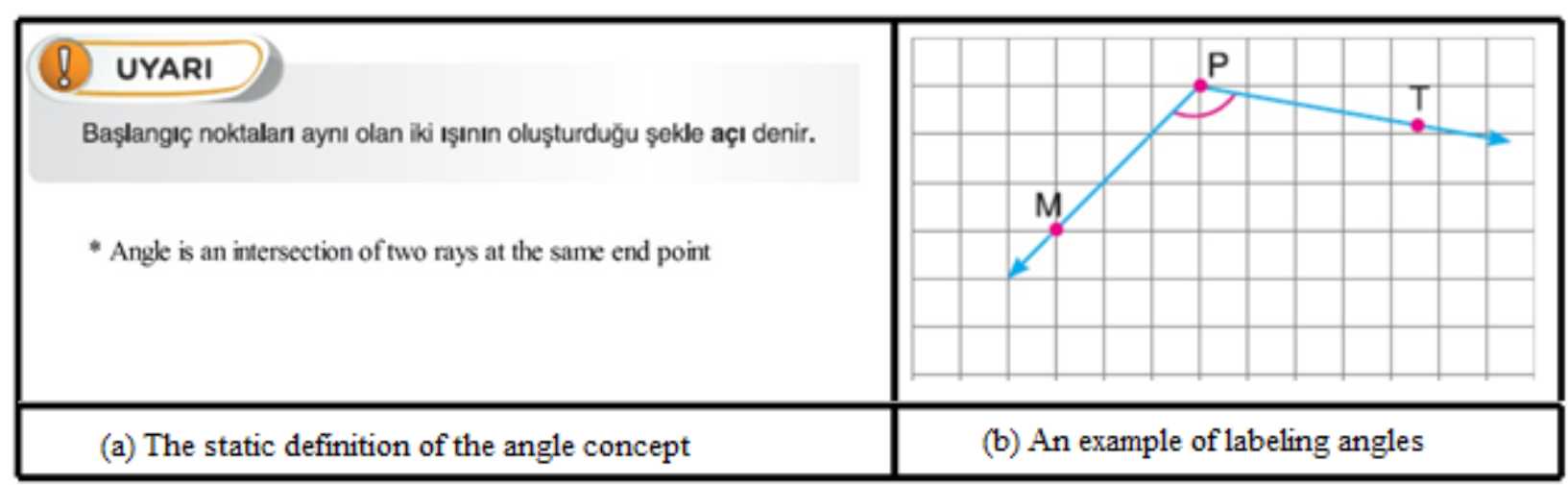

Figure 2. (a) The static definition of the angle concept and (b) an example of labeling angles

Following this example is a caution indicating that whether the arms are long or short, the angle size stays the same (Figure 3). Certainly, this caution addresses one of the so-called misconceptions concerning the angle concept.

\section{UYARI}

Açının kenarlannın uzun voya kısa clması açını ôlçôsûnû dogiștirmez.

Figure 3. A caution (whether the arms are long or short, the angle size stays the same)

Afterwards, there are an example and its solution for labelling angles which are drawn on the bicycle picture (Figure 4). The solution indicate that the angle BOD can be shown as (BOD), (DOB) or O whereas the angle FEG can be demonstrated as (FEG), (GEF) or E.

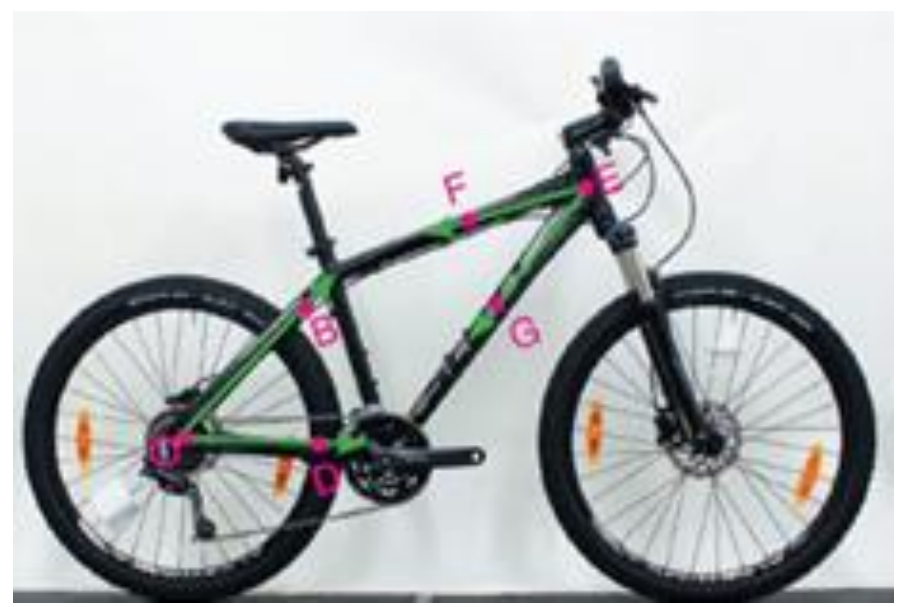

Figure 4. A bicycle picture

Thereafter is a section on constructing a perpendicular at a point on and then a point not on a line, illustrated by a picture of a tower crane. Drawing a perpendicular is demonstrated by examples. For instance, place your compass at 
$1 \mathrm{~cm}$ right of point $\mathrm{D}$ and make a small arc (Figure 5). Without changing the span of the compass, place your compass at $1 \mathrm{~cm}$ left of point $\mathrm{D}$ and make another arc which crosses the other one (Figure 6). With your straightedge, connect the intersection of these arcs to point D (Figure 7).

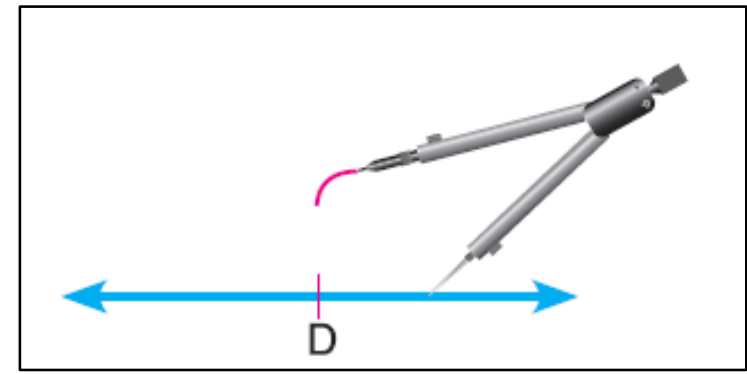

Figure 5. Making a small arc at $1 \mathrm{~cm}$ right of point $\mathrm{D}$

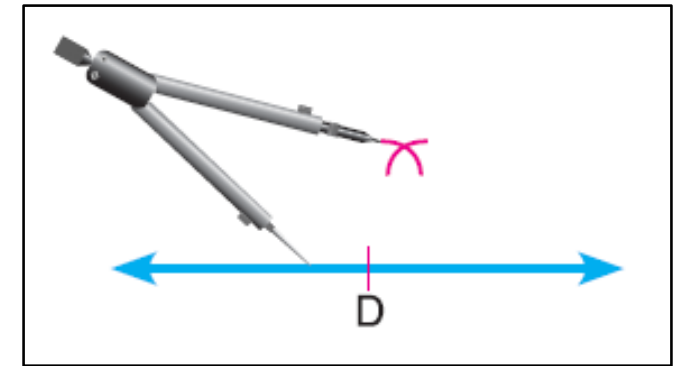

Figure 6. Making a small arc at $1 \mathrm{~cm}$ left of point D

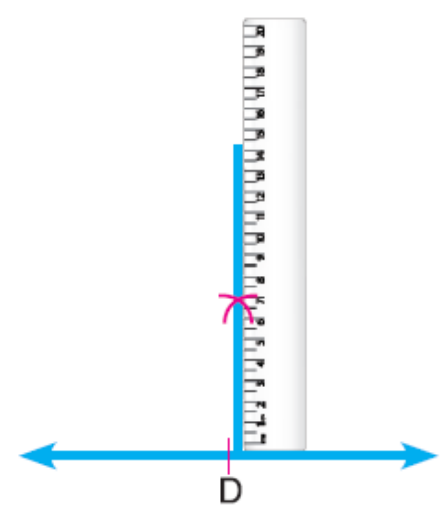

Figure 7. Connecting the intersection of these arcs to point D

In short, the grade 6 mathematics textbook provides a static definition of the angle concept. In addition, the right angle is given different than its prototype, yet its arms are shown as parallel to the paper's margins (see Figure 8). Additionally, the grade 6 mathematics textbook highlights that the size of the angle is independent from the size of its arms, yet other identified misconceptions in previous studies are not mentioned. Finally, the relations to everyday concepts and the angle concept are only illustrated by pictures of a bicycle and a tower crane, and students were asked to describe what they see in these pictures. Clearly, only a limited representation of the relations to everyday concepts and the angle concept are given in the grade 6 mathematics textbook.
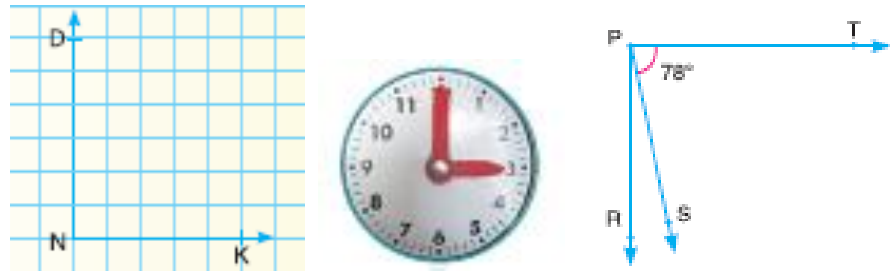

Figure 8. Examples of the right angle

\subsection{Research questions}

Comprehending the angle concept is crucial to the development of students' understanding of geometry because angles are the one of the fundamental elements in geometric shapes [40,41]. Despite the relevance of the angle concept to knowledge of geometry, studies have found that elementary students develop misconceptions because it is a multifaceted concept and their textbooks provide limited information about it. For example, the grade 6 mathematics textbook addresses only one misconception that is 'the size of an angle depending on the size of its 
arms', but any information on other misconceptions is not provided. Hence, this study aimed to explore grade 6 students' misconceptions on the angle concept.

\section{Methodology}

A survey method was employed to identify grade 6 students' misconceptions about the angle concept. In addition to having the power to investigate the phenomena which have already occurred, the survey method might allow researchers to use nonprobability sampling methods including a purposive sampling method $[42,43]$. The purposive sampling method could be chosen when researchers were interested in the specific type of person such as students whose mathematics grades were 4 or 5 out of 5 [44].

A purposive sampling method was used to recruit 233 grade 6 students studying in eight classes in two elementary schools of Trabzon, Turkey. Their mathematics grades were 4 or 5 out of 5 . Even though there is no consensus among researchers concerning the minimum number of participants in such surveys, Cohen, Manion and Morrison [45] suggested a minimum of 100 participants. The number of participants in this study is thought satisfactory.

\subsection{Data collection}

The data for this study were gathered via conceptually oriented questions having the capacity to diagnose students' misconceptions [46]. To answer conceptually oriented questions, students were not required to perform any calculations; instead, they needed to use a coherent understanding of underlying principles and concepts [47-49].

The questions used in this study were prepared in three steps. First, the learning competencies specified for the grade 6 mathematics curriculum [50] related to the angle concept were reviewed. These learning competencies included the definition and representation of angles, adjacent, complementary, supplementary and vertical angles followed by constructing a perpendicular line to a line through a point. Thereafter, studies aiming to explore students' misconceptions on the angle concept were examined. Finally, six questions were designed with respect to the learning competencies consisting of the definition and representation of the angles as well as drawing a perpendicular line to a line through a point.

In the first question, students were asked to identify angles among shapes (see figure 9) as well as to recognize the straight angle and right angles in different orientations.

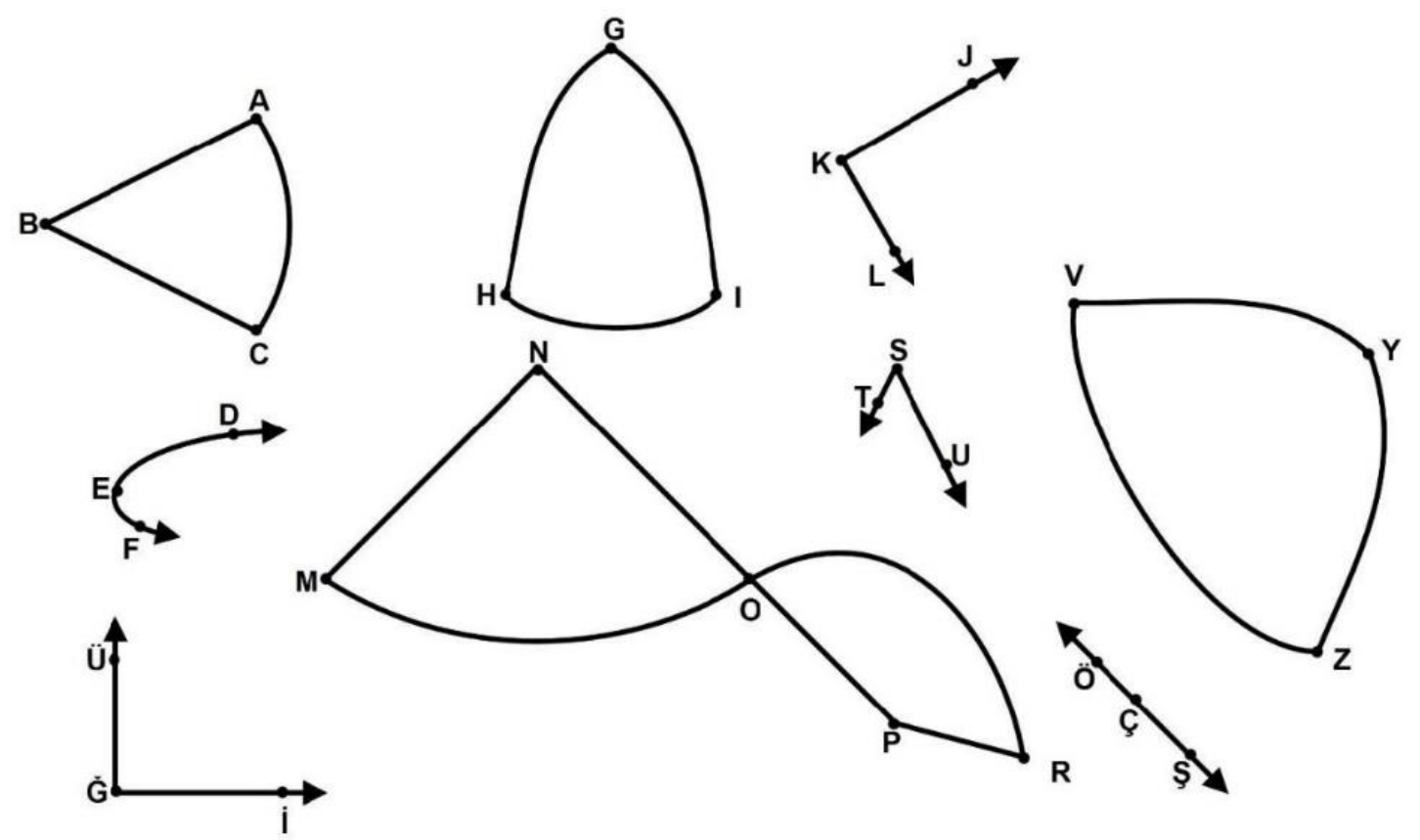

Figure 9. Geometric shapes in the first question 
The second question aimed to find whether students determine the size of angles based on the size of arc between the arms of the angles. To do so, three concentric circles with center $\mathrm{O}$ and two radiuses of the outer circle were given (see figure 10), and the intersections of the radiuses with these circles were named. Then, students were asked to compare the size of $\mathrm{AOB}, \mathrm{GOD}$ and EOF angles.

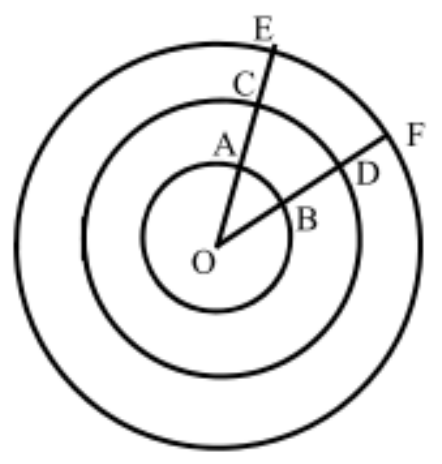

Figure 10. Three concentric circles in the second question

The purpose of the third and sixth questions was to measure how students can adapt the angle concept to real life. In these questions, there were an observer and a barrier, and students were asked to colour the hidden area behind the barrier (see figures 11 and 12).
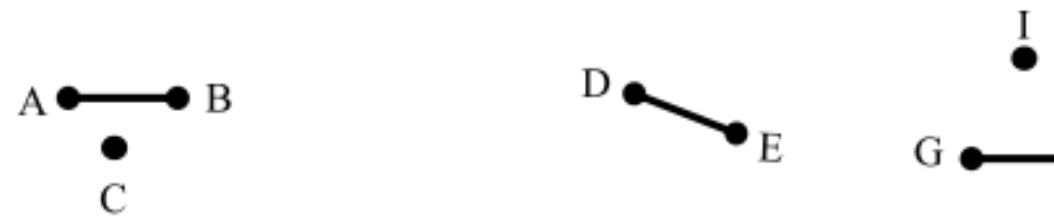

\section{F}

Figure 11. An observer and a barrier in the third question
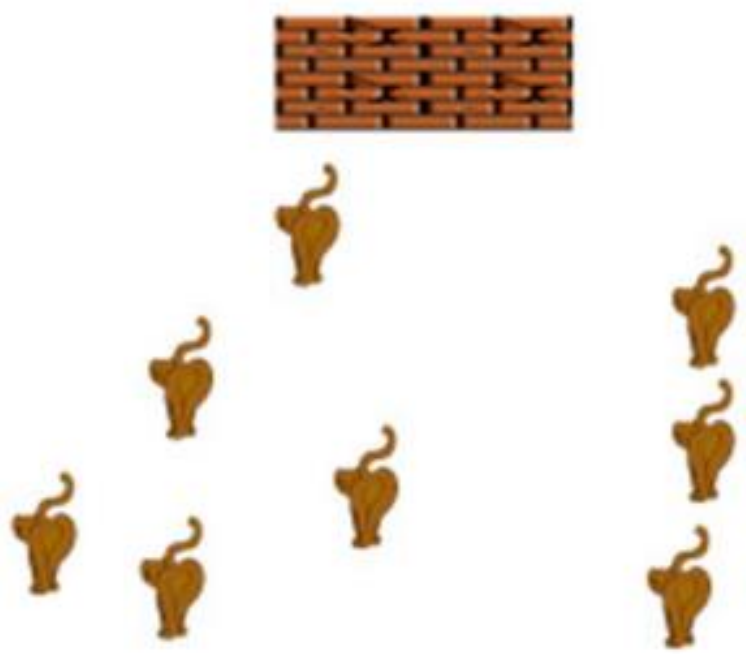

Figure 12. A wall, dog and cats in the sixth question 
In the fourth question, students were asked to compare the size of angles having different sizes of arms (see figure 13).
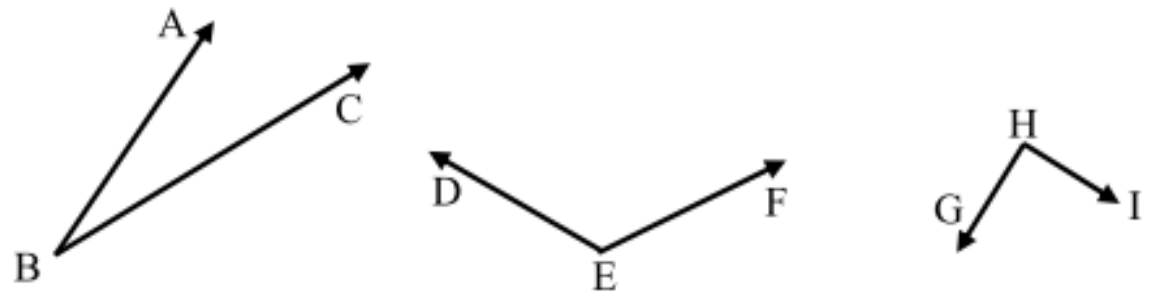

Figure 13. Angles having different sizes of arms in the fourth question

In the fifth question, students were required to construct a perpendicular line to a line both through an external point and at a point on the line (see figure 14).
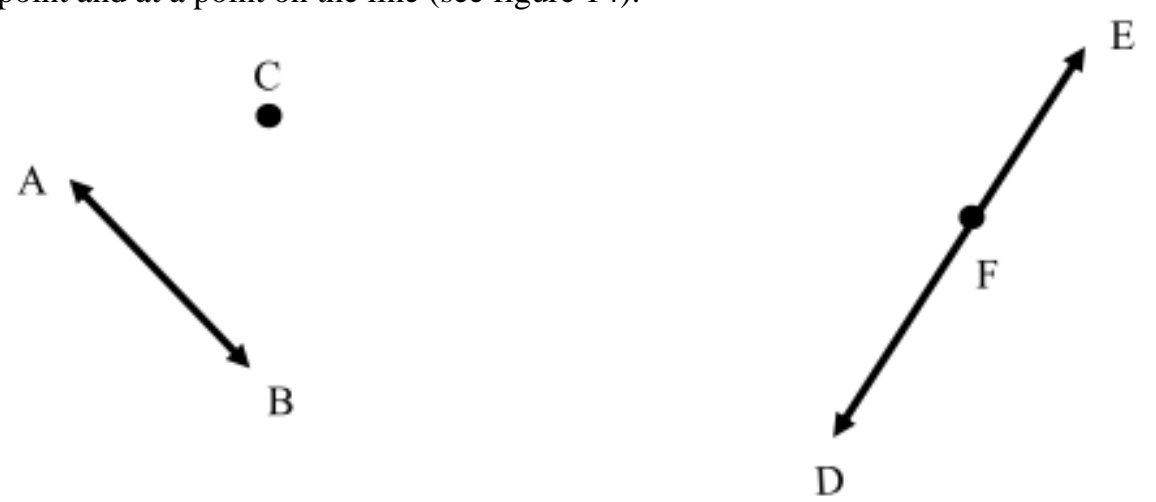

Figure 14. Lines with an external point and at a point on the line in the fifth question

Briefly, no procedures were required to answer these questions. Through these questions, we aimed to assess students' conceptual understanding of the angle concept and to explore how well students can adapt the angle concept to real life. Additionally, both two experts and a mathematics teacher reviewed and affirmed these questions in terms of their content and face validity.

\subsection{Procedure}

The pilot and actual study were conducted after students were taught the learning competencies of the angle concept in the grade 6 mathematics curriculum. The pilot study was performed with 68 grade 6 students in order to test the understandability and functionality of the questions, and it took 40 minutes. We concluded that the quality of the questions was comprehensive enough to explore students' misconceptions about the angle concept within 40 minutes. The school principals of the two elementary schools were first informed about the purpose of this study and their permission obtained to conduct this research in classrooms with students whose mathematics grades were 4 or 5 out of 5 . Data were collected by researchers over two days at school A and three days at school B.

\subsection{Data analysis}

The data were analysed in five steps (see Figure 15). To begin with, categories were created by two researchers based on previous studies that aimed to investigate students' errors and misconceptions on the angle concept. Then, students' answers were marked as either correct or incorrect. Afterwards, incorrect answers were compared with the categories generated from the literature review, and the similarities and differences in the comparison were coded by two researchers. Cohen's kappa coefficient was calculated as 0.97 indicating that the inter-rater agreement was almost perfect, ranging between 0.81 and 1.00 [51-53], and coding discrepancies were discussed and resolved through consensus. Finally, the frequency and percentage of the resultant codes were demonstrated in tables. 


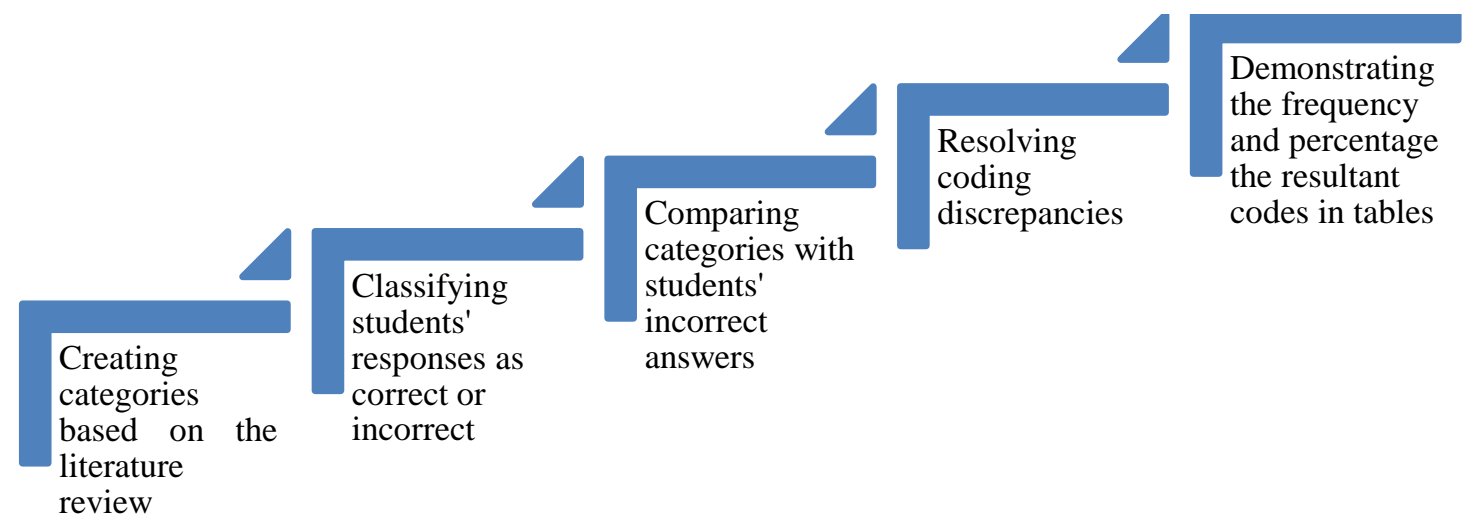

Figure 15. Data analysis process

\section{Findings}

The frequencies and percentages of codes for each of the six questions are shown in the tables. Answers illustrating students' reasoning are also provided.

\subsection{Findings of the first question}

The first question consisted of various shapes, and students were asked to color the angles and to write the right angles. As illustrated in Table 1, while 9 students did not answer this question, 83 students correctly answered this question, 75 of the students recognized the angle JKL as a right angle and 92 of the respondents incorrectly named the shapes VYZ, HGI and DEF as angles.

Table 1. Codes, frequencies and percentages for the first question

\begin{tabular}{lll}
\hline Codes & Frequencies & Percentages (\%) \\
\hline Correct answers & 83 & 36 \\
\hline Could not distinguish right angles in different orientations & 75 & 32 \\
\hline $\begin{array}{l}\text { Either three points on the arcs or the intersection of two arcs represent an } \\
\text { angle }\end{array}$ & 92 & 39 \\
\hline No answer & 9 & 4 \\
\hline
\end{tabular}

\subsection{Findings of the second question}

In the second question, there were three concentric circles with centre $\mathrm{O}$ and two radiuses of the outer circle, and the intersection of the radiuses with these circles was named. Then, students were asked to compare the size of AOB, GOD and EOF angles.

As seen in Table 2, only 100 of 233 students answered correctly and 47 students did not answer this question. Erroneously, 68 students indicated that the size of an angle increases when the area between the arms of the angle and the arc is increased. Another 15 students erroneously thought that the size of the angle is related to the size of the arc.

Table 2. Codes, frequencies and percentages for the second question

\begin{tabular}{lll}
\hline Codes & Frequencies & Percentages (\%) \\
\hline Correct answers & 100 & 43 \\
\hline The size of the angle related to the size of the arc & 15 & 6 \\
\hline The size of the angle related to the area of the sector & 68 & 29 \\
\hline Other incorrect answers & 3 & 1 \\
\hline No answer & 47 & 20 \\
\hline
\end{tabular}

When S6's answer (see Figure 16) was examined, S6 expressed that the angle EOF is the largest angle because the arc EF is the greatest arc, and angle AOB is the smallest angle because the arc AB is the smallest arc. On the other hand, S2 (see Figure 16) pointed out that the area of the sector EF is the biggest, so the angle EOF is the 
largest angle, and the area of the sector $\mathrm{AB}$ is the smallest, so the angle $\mathrm{AOB}$ is the smallest angle. Additionally, students who answered correctly implied that three angles have the same vertex and arms (see Figure 17).

\begin{tabular}{|c|c|}
\hline $\begin{array}{l}\text { S7's answer (Because the arcs between the angles' } \\
\text { arms are getting bigger) }\end{array}$ & $\begin{array}{l}\text { S2's answer (The angle AOB is the smallest, because the } \\
\text { area of the angle AOB is the smallest. The angle COD is } \\
\text { slightly larger than the area of the angle AOB. the angle } \\
\text { EOF is the largest angle, because its area is larger than } \\
\text { other two angles) }\end{array}$ \\
\hline $\begin{array}{l}\text { Gũnkí ocilarin } \\
\text { arasindaki ôlaũ } \\
\text { yuvarlaklar gittikge } \\
\text { büyüyor. }\end{array}$ & 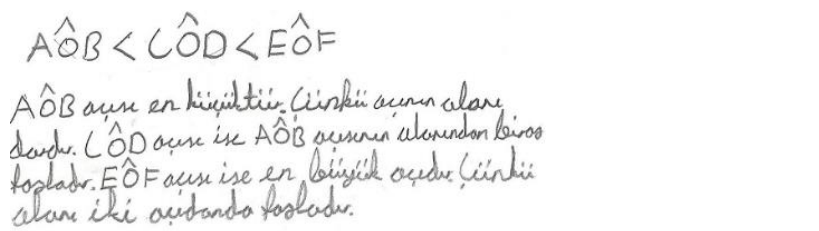 \\
\hline
\end{tabular}

Figure 16. Examples of students' erroneous responses to the second question

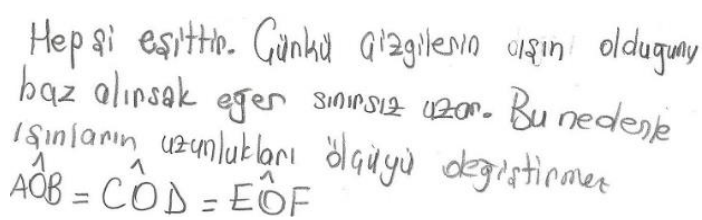

Figure 17. Examples of students' correct responses for the second question (All angles are equal, because if we assume that these lines are rays, the length of these rays are infinity. Therefore, the length of the rays does not change the size of the angles)

\subsection{Findings of the third question}

This question included an observer and barrier, and students were asked to colour the hidden area behind the barrier. As seen in Table 3, only 13 students correctly answered this question. Here, 57 students were not able to answer this question. While 59 participants coloured the area between the observer and the barrier (see Figure 18), 25 participants drew rays from the observer to both sides of the observer, and coloured the area covered by the rays, the observer and barrier (see Figure 19). Moreover, 79 students constructed two perpendicular lines at both ends of the barrier, and coloured behind the barrier (see Figure 20).

Table 3. Codes, frequencies and percentages for the third question

\begin{tabular}{lcc}
\hline Codes & Frequencies & Percentages (\%) \\
\hline Correct answers & 13 & 6 \\
\hline Coloured the area between the observer and the barrier & 59 & 25 \\
\hline $\begin{array}{l}\text { Drew rays from the observer to both sides of the observer, and coloured the } \\
\text { area covered by the rays, the observer and barrier }\end{array}$ & 25 & 11 \\
\hline $\begin{array}{l}\text { Constructed two perpendicular lines at the both end of the barrier, and colored } \\
\text { behind the barrier }\end{array}$ & 79 \\
\hline No answer & 54 & 34 \\
\hline
\end{tabular}




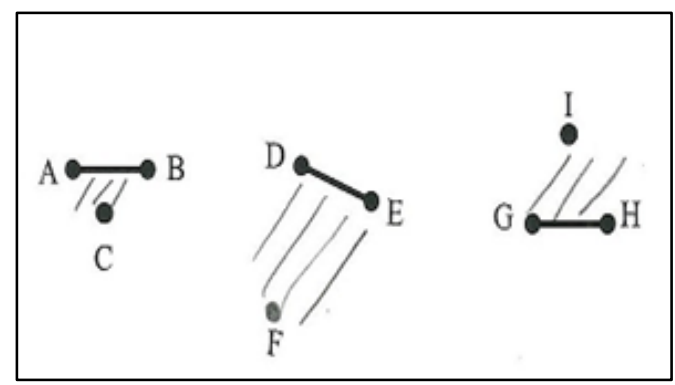

Figure 18. Colouring the area between the observer and the barrier

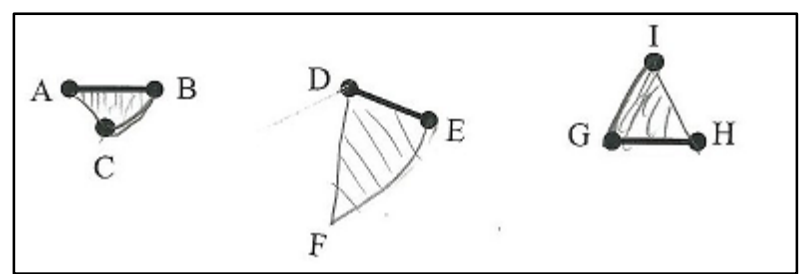

Figure 19. Drawing rays from the observer to both sides of the observer, and coloured the area covered by the rays, the observer and barrier

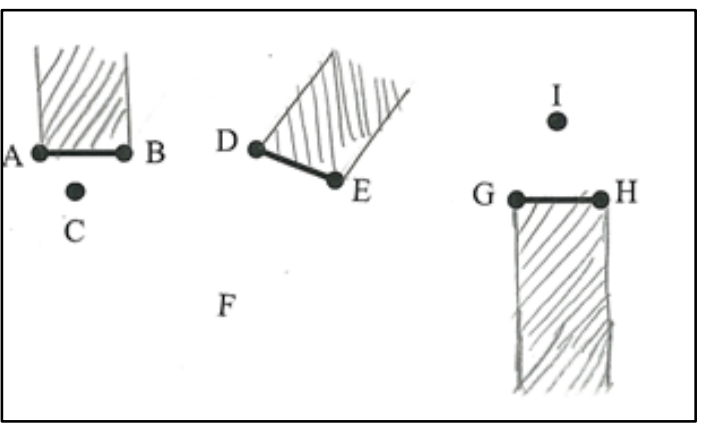

Figure 20. Constructing two perpendicular lines at both ends of the barrier, and coloured behind the barrier

\subsection{Findings of the fourth question}

The fourth question aimed to determine if students can construct a perpendicular line to a line though a point. Table 4 demonstrates students' responses to this question. While 98 students answered correctly, 18 students did not respond. Additionally, 71 students claimed that a perpendicular line cannot be drawn if the point is on the line. We also found that $20 \%$ of students tended to draw a perpendicular line which is parallel to the paper's long side (Figure 21).

Table 4. Codes, frequencies and percentages for the fourth question

\begin{tabular}{lll}
\hline Codes & Frequencies & Percentages $(\%)$ \\
\hline Correct answers & 98 & 42 \\
\hline Ignored the orientation of a line & 46 & 20 \\
\hline Perpendicular line cannot be drawn if the point is on the line & 71 & 30 \\
\hline No answer & 18 & 8 \\
\hline
\end{tabular}

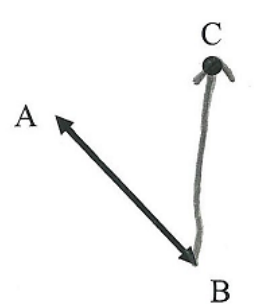

B

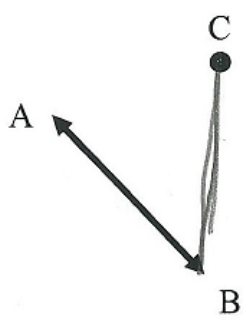


Figure 21. Drawing a perpendicular line which is parallel to the paper's long side

\subsection{Findings of the fifth question}

The fifth question consisted of a dog, a wall and eight cats, and students were asked to identify the cats which the dog can see. As seen in the Table 5, 90 students responded correctly by drawing oblique lines from the observer to both end of the wall (Figure 22). Some 77 students did not use any strategies, and their reasonings were given as: 'the dog can see the furthest cats from the wall', 'the dog can see the cats which are not behind the wall', 'the dog can see the cats which are at the left and right sides of the wall' (see S129's answer in Figure 23). Another 66 students drew two perpendicular lines at both end of the wall, and circled the cats between these lines (see S107's answer in Figure 23).

Table 5. Codes, frequencies and percentages for the fifth question

\begin{tabular}{lll}
\hline Codes & Frequencies & Percentages (\%) \\
\hline Correct answer & 90 & 39 \\
\hline Did not use any strategies & 77 & 33 \\
\hline $\begin{array}{l}\text { Drew two perpendicular lines at the both end of the wall, and circled the cats } \\
\text { between these lines }\end{array}$ & 66 & 28 \\
\hline
\end{tabular}

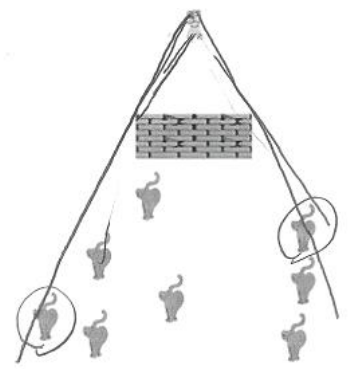

$$
\begin{aligned}
& \text { kiojpetin tarm olorak göz hizasindan duvara temas etmeden } \\
& \text { bir dogru cizince bu sonuca ulaştim. }
\end{aligned}
$$

Figure 22. Examples of students' correct responses for the fifth question (I reached the conclusion when I draw oblique lines which did not cross the wall from the dog to the wall.)

\begin{tabular}{l}
$\begin{array}{l}\text { S107's answer (drew two perpendicular lines at the both } \\
\text { end of the wall, and circled the cats which are not } \\
\text { between these lines) }\end{array} \begin{array}{l}\text { S129's answer (the dog can see the cats which are not } \\
\text { behind the wall) }\end{array}$ \\
\hline
\end{tabular}


Figure 23. Examples of students' erroneous responses to the fifth question

\subsection{Findings of the sixth question}

In the sixth question, students were asked to compare the size of three angles having different sizes of arms. As illustrated in Table 6, although 90 students responded correctly, 17 students did not answer this question. One hundred and twenty-six participants drew arcs to determine the size of angles of whom 114 felt that the size of an angle is related to the size of the arc (see S39's answer in Figure 24), while another 12 students erroneously correlated the size of angles with the area of the sector (see S208's answer in Figure 24).

Table 6. Codes, frequencies and percentages for the sixth question

\begin{tabular}{lll}
\hline Codes & Frequencies & Percentages (\%) \\
\hline Correct answers & 90 & 39 \\
\hline The size of the angle related to the size of the arc & 114 & 49 \\
\hline The size of the angle related to the area of the sector & 12 & 5 \\
\hline No answer & 17 & 7 \\
\hline
\end{tabular}

S39's answer (If these arcs I draw represent the size of
angle, the order of the angles are correct. In other words, I
think the largest arc that I draw illustrates the largest
angle.)

Figure 24. Examples of students' erroneous responses for the sixth question

\section{Discussions and conclusions}

The results of our research confirm that many grade 6 students in Turkey can hold misconceptions and have difficulties in grasping the conceptual understandings of the angle concept. First of all, many students assumed that the intersection of two arcs is an angle. In the first study question, students were asked to color the angles among different shapes. In total, 39\% of students coloured the intersection of two arcs as an angle. Similarly, Keiser [12] investigated that some students mistakenly believed that the letter R and P formed angles as well as they claimed that $\mathrm{O}$ and $\mathrm{S}$ did form angles because they could not find any vertex points in these letters.

Another misconception was that students could not recognize the $180^{\circ}$ angle. We found that $32 \%$ of students were unable to recognize the $180^{\circ}$ angle. The reason for this misconception is probably due to only a static definition of the angle concept being given in the grade 6 mathematics textbook applied in Turkey. According to this definition, an angle was the space between two rays with a common end point. Woodward [27] claimed that this definition caused difficulties in identifying the $180^{\circ}$ angle. Likewise, Keiser [12] found that students did not recognize the $180^{\circ}$ angle because they could not see the two rays. Consequently, students should know the dynamic definition of the angle concept, yet while Mitchelmore and White [16] found that less than $10 \%$ of grade 4 students knew the dynamic definition of the angle concept, Foxman and Ruddock [54] reported that only $4 \%$ of students aged 15 could correctly identify the dynamic definition of the angle concept.

In addition, many students had difficulty in distinguishing right angles whose arms are not parallel to the paper's margins. We found that $32 \%$ of students could not recognize the right angle in different orientations. Likewise, The Trends in International Mathematics and Science Study 2011 international database [55] reported that 47\% of grade 
4 students in Turkey and 36\% of grade 4 students participating in their research could not distinguish the right angle in different orientations. Similar results are found in other studies as well [22,28,29,56,57]. This misconception may originate from the representations used in textbooks where the arms of the prototype right angle always appear parallel to the paper's margins and have a conventional symbol of a right angle $[28,29,58]$.

Furthermore, we found that many students assume that the size of an angle depends on the radius of the arc marking the angle. In the sixth question, $49 \%$ of students drew the arc making the angle and decided the size of angle based on the arc. We found that $6 \%$ of students employed the same strategy for answering the other six questions. Similarly, Mitchelmore [22] reviewed studies on the angle concept and detected that many students theorize that the size of an angle is related to the radius of the arc marking the angle.

Additionally, we found that students assume that the size of an angle depends on the area of the sector. In the second question, $29 \%$ of our sample first ordered the area of sectors of three concentric circles. Then, they ordered the size of angles relying on the area of sectors. This strategy was also used by $5 \%$ of students for answering the second question. Likewise, this misconception was investigated by Bratitsis, Tatsis and Amanatidou [59]. They found that colouring three concentric circles (see Figure 25) caused confusion for students.

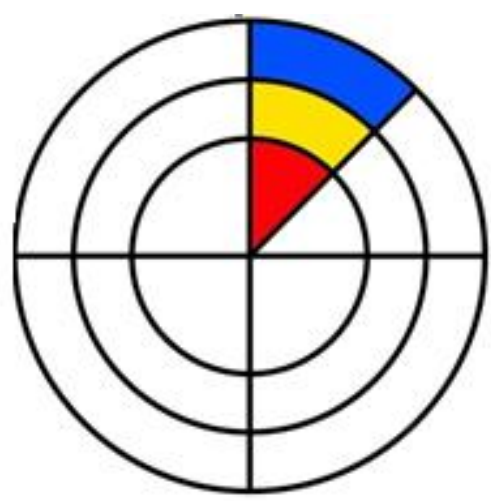

Figure 25. Screenshot of the three concentric circles

Moreover, we found that students in Turkey faced difficulties in adapting the angle concept to real life. Only $6 \%$ of students correctly answered the third question, and 39\% the fourth question. The most used incorrect strategy was to construct two perpendicular lines at the ends of the barrier and to colour between these lines. While $39 \%$ of students used this strategy in the third question, $28 \%$ of students used that strategy in the fifth question. Likewise, Munier, Devinci and Merle [30] detected that $27 \%$ of students employed this incorrect strategy. Munier and Merle [23] also found that this incorrect strategy was used by $22 \%$ of students.

Finally, students had difficulties in constructing perpendicular lines. We determined that nearly one in three students thought that a perpendicular line at a point on the line cannot be drawn. One in five of them also constructed a perpendicular line at a point on the line as if the line was parallel to the paper's short side. In other words, students ignored the orientation of the lines. This difficulty extended to drawing a perpendicular height to the base of a triangle, because students believed that the base of a triangle should be parallel to the paper's short side [60].

While the data of this study were collected from students whose mathematics scores were 4 or 5 out of 5 , we found that these high achievers nevertheless hold several misconceptions about the angle concept. We inferred that some of these misconceptions might occur because of the definitions, representations or examples given in the grade 6 mathematics textbook used in Turkey. Previously, Kablan, Baran and Hazer [61] examined the characteristics of geometry questions in the grade 6-8 mathematics textbook and reported that while only 3.3\% of questions aimed to measure students' analysis and creativity skills, $60.7 \%$ of questions intended to measure students' understanding skill. Therefore, being high achievers depended on how well students perform the rules and algorithms that they were taught. Such high achievers might have misconceptions and concomitant difficulties in mathematics [62]. Additionally, mathematics textbooks rarely indicate students' misconceptions and provide examples addressing them. We investigated that only one misconception regarding the angle concept was included in the grade 6 mathematics textbook used in Turkey. Similarly, in the project 2061, it was reported that 12 mathematics textbooks 
used in the USA were examined, but none of them could adequately help students overcome their misconceptions in mathematics $[63,64]$.

Based on our findings and those in the literature, we recommend that grade 6 mathematics textbooks used in Turkey are revised to incorporate:

- The dynamic definition of the angle concept in addition to the static one. And, examples which are suitable for both definitions should be provided in mathematic textbooks (see Figure 26).

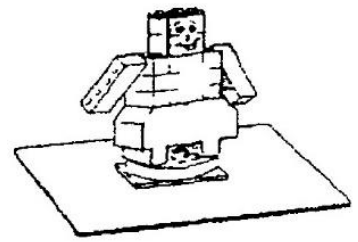

\section{Doll (unlimited turn)}

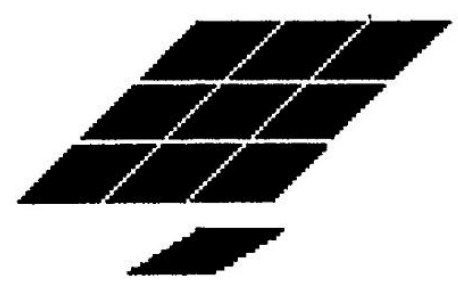

Tiles (plane corner)
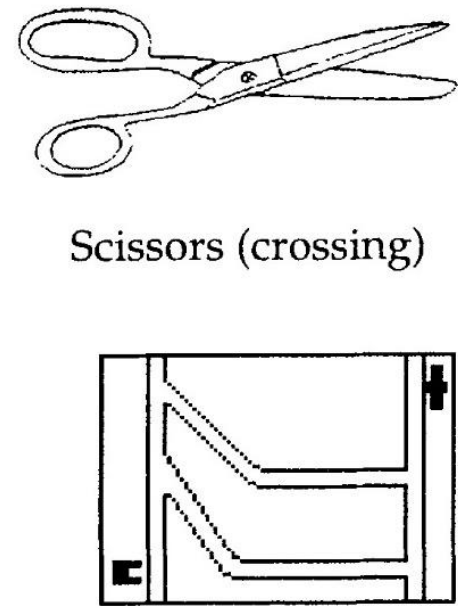

Roads (bent object)

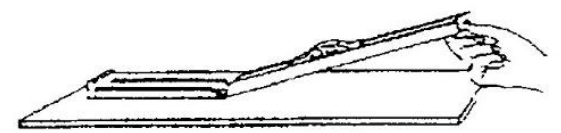

Road (linear slope)

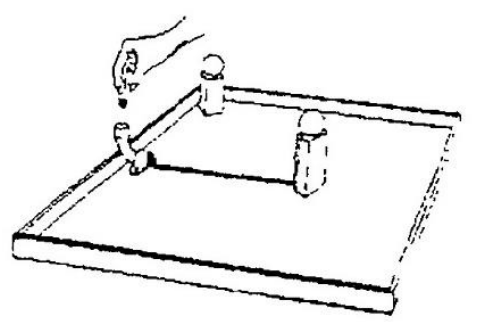

Cricket (bent path)

Figure 25. Sample representations for the statics and dynamic definition of the angle concept [16]

- Hands-on activities that can be enriched by body-based tasks.

- References to dynamic geometry software like Logo, Geogebra, geometer's Sketchpad and guidance for use of such programs in the teacher's handbook.

In GeoGebra software, students may be asked to rotate a ray around its endpoint by using a 'slider' and 'rotate around point'. Therefore, students may gain an awareness of the dynamic definition of the angle concept. Similarly, right angles may be rotated around a point to increase recognition of right angles in different orientations.

- A variety of activities, each of which is devised with misconceptions and common errors about the angle concept in mind.

Activities related to adapting the angle concept to real life may be used in the grade 6 mathematics textbook. In the playground, an opaque screen and a chair may be placed. While one student sits in the chair, the others stay on other side of the opaque screen with their school bags arranged in a way that the student in the chair cannot see any of them. One by one, students holding their bags may be asked to move sideways and put their bag on the ground as soon as they can be observed by the student sitting in the chair. Afterwards, students may be asked to identify the created geometric shape and its features. Through this example, students will be able to visualize the angle concept.

For instance, students may be asked to draw an angle with a protractor and to construct an arc as seen in Figure 15. Thereafter, a teacher may ask the students to measure the size of the angle with the protractor. Then, students may be asked to draw another arc marking the angle, after which they may be asked to measure the size of the angle with the protractor. This activity may be repeated until they realize that the size of the angle is independent from the size of the arcs marking the angle. 


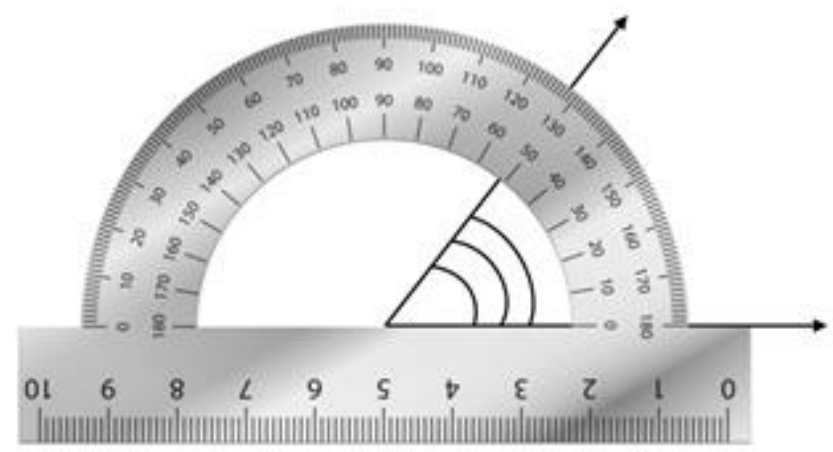

Figure 15. Using the protractor to resolve misconception

In future studies, we recommend that teachers' in-class practices while teaching the angle concept should be observed. Such observation is likely to provide ample evidence for why so many students encounter difficulty understanding and applying the concept.

\section{References}

[1] Piaget J. The origins of intelligence in children. New York, USA: International Universities Press; 1952.

[2] Ausubel DP. Educational Psychology: A Cognitive View. 2nd Revised edition edition. New York: Holt McDougal; 1978.

[3] Vosniadou S. Capturing and modeling the process of conceptual change. Learn. Instr. 1994;4:45-69.

[4] Bofferding L. Negative integer understanding: Characterizing first graders' mental models. J. Res. Math. Educ. 2014;45:194-245.

[5] Molina M, Ambrose R, Castro E. In the transition from arithmetic to algebra: misconceptions of the equal sign. 28th Int. Group Psychol. Math. Educ. Bergen, Norway: The European Mathematical Information Service Electronic Edition; 2004.

[6] Booth JL, Koedinger KR. Key misconceptions in algebraic problem solving. In: Love BC, McRae K, Sloutsky VM, editors. Proc. 30th Annu. Conf. Cogn. Sci. Soc. Austin, USA: Cognitive Science Society; 2008. p. 571-576.

[7] Biber Ç, Tuna A, Korkmaz S. The mistakes and the misconceptions of the eighth grade students on the subject of angles. Eur. J. Sci. Math. Educ. 2013;1:50-59.

[8] Clements DH, Battista MT. Geometry and spatial reasoning. In: Grouws DA, editor. Handb. Res. Math. Teach. Learn. Proj. Natl. Counc. Teach. Math. New York, USA: Macmillan Publishing Co, Inc; 1992. p. $420-464$.

[9] Kabaca T, Karadag Z, Aktumen M. Misconception, cognitive conflict and conceptual changes in geometry: a case study with pre-service teachers. Mevlana Int. J. Educ. 2011;1:44-55.

[10] Henderson DW, Taimina D. Experiencing geometry: Euclidean and non-Euclidean with history. 3rd ed. New York, USA: Prentice Hall; 2005.

[11] Keiser JM. The role of definition. Math. Teach. Middle Sch. 2000;5:506-511.

[12] Keiser JM. Struggles with developing the concept of angle: Comparing sixth-grade students' discourse to the history of the angle concept. Math. Think. Learn. 2004;6:285-306. 
[13] Kim O-K, Lee JH. Representations of Angle and Lesson Organization in Korean and American Elementary Mathematics Curriculum Programs. KAERA Res. Forum. 2014;1:28-37.

[14] Mitchelmore MC, White P. Development of angle concepts by progressive abstraction and generalisation. Educ. Stud. Math. 2000;41:209-238.

[15] Wilson PS, Adams VM. A Dynamic Way to Teach Angle and Angle Measure. Arith. Teach. 1992;39:6-13.

[16] Mitchelmore MC, White P. Development of angle concepts: A framework for research. Math. Educ. Res. J. 1998;10:4-27.

[17] Filippaki N, Papamichael Y. Tutoring conjunctions and construction of geometry concepts in the early childhood education: The case of the angle. Eur. J. Psychol. Educ. 1997;12:235-247.

[18] Fyhn AB. A climbing girl's reflections about angles. J. Math. Behav. 2006;25:91-102.

[19] Kieran C. Logo and the notion of angle among fourth and sixth grade children. In: Hoyles C, Burton L, editors. Proc. Tenth Annu. Conf. Int. Group Psychol. Math. Educ. City University, London, England; 1986. p. 99-104.

[20] Bustang B, Zulkardi Z, Darmawijoyo D, et al. Developing a Local Instruction Theory for Learning the Concept of Angle through Visual Field Activities and Spatial Representations. Int. Educ. Stud. 2013;6:5870 .

[21] Clements DH, Burns BA. Students' development of strategies for turn and angle measure. Educ. Stud. Math. 2000;41:31-45.

[22] Mithcelmore MC. Young students' concepts of turning and angle. Cogn. Instr. 1998;16:265-284.

[23] Munier V, Merle H. Interdisciplinary Mathematics-Physics Approaches to Teaching the Concept of Angle in Elementary School. Int. J. Sci. Educ. 2009;31:1857-1895.

[24] Devichi C, Munier V. About the concept of angle in elementary school: Misconceptions and teaching sequences. J. Math. Behav. 2013;32:1-19.

[25] Clausen-May T. Another angle on angles. Aust. Prim. Math. Classr. 2008;13:4-8.

[26] Lehrer R, Guckenberg T, Lee O. Comparative study of the cognitive consequences of inquiry-based Logo instruction. J. Educ. Psychol. 1988;80:543-553.

[27] Woodward E. Different Angles on Measuring Angles. Sch. Sci. Math. 1978;78:385-387.

[28] Gal H. From Another Perspective - training teachers to cope with problematic learning situations in geometry. Educ. Stud. Math. 2011;78:183-203.

[29] Gal H, Linchevski L. To see or not to see: analyzing difficulties in geometry from the perspective of visual perception. Educ. Stud. Math. 2010;74:163-183.

[30] Munier V, Devichi C, Merle H. A Physical Situation as a Way to Teach Angle. Teach. Child. Math. 2008;14:402-407.

[31] Kajander A, Lovric M. Mathematics textbooks and their potential role in supporting misconceptions. Int. J. Math. Educ. Sci. Technol. 2009;40:173-181.

[32] Markowsky G. Misconceptions about the golden ratio. Coll. Math. J. 1992;23:2-19. 
[33] Luneta K. Understanding students' misconceptions: An analysis of final Grade 12 examination questions in geometry. Pythagoras. 2015;36:1-11.

[34] Smith CP, King B, Hoyte J. Learning angles through movement: Critical actions for developing understanding in an embodied activity. J. Math. Behav. 2014;36:95-108.

[35] Başer N. A case study of elementary mathematics teachers' views of their and students' textbook usage and of mathematics textbooks' characteristics [Internet] [Master Thesis]. [Ankara, Turkey]: Middle East Technical University; 2012 [cited 2016 Apr 23]. Available from: http://etd.lib.metu.edu.tr/upload/12614403/index.pdf.

[36] Noss R, Baki A. Liberating school mathematics from procedural view. Hacet. Üniversitesi Eğitim Fakültesi Derg. 1996;12:179-182.

[37] Özgeldi M. Explaining Dimensions of Middle School Mathematics Teachers' Use of Textbooks. Mersin Univ. J. Fac. Educ. 2012;8:24-36.

[38] Özgeldi M, Çakıroğlu E. A study on mathematıcs teachers'use of texbooks in instructional process. In: Pytlak M, Rowland T, Swoboda E, editors. Proc. Seventh Congr. Eur. Soc. Res. Math. Educ. CERME 7. Rzeszów, Poland: University of Rzeszów, Poland, on behalf of the European Society for Research in Mathematics; 2011. p. 2349-2355.

[39] Bağcı O. Ortaokul matematik 6 ders kitabı [Grade 6 Mathematics Textbook]. Ankara, Turkey: Dikey Yayınc1lı; 2014.

[40] Browning CA, Garza-Kling G, Sundling EH. What's Your Angle on Angles? Teach. Child. Math. 2007;14:283-287.

[41] Yazgan G, Argün Z, Emre E. Teacher sceneries related to "Angle Concept": Turkey case. Procedia - Soc. Behav. Sci. 2009;1:285-290.

[42] Çepni S. Araştırma ve proje çalışmalarına giriş [Introduction to research and project studies]. Trabzon, Turkey: Celepler Matbaacilık; 2014.

[43] DePoy E, Gitlin LN. Introduction to research: Understanding and applying multiple strategies. 4th ed. St. Louis, Missouri, USA: Elsevier Health Sciences; 2011.

[44] Beins BC, McCarthy MA. Research methods and statistics. New Jersey, USA: Pearson Higher Education; 2011.

[45] Cohen L, Manion L, Morrison K. Research methods in education. 7th ed. London, UK: Routledge; 2013.

[46] Shannon A. Keeping score. Washington, USA: National Academies Press; 1999.

[47] Kadijević Đ. Conceptual tasks in mathematics education. Teach. Math. 1999;2:59-64.

[48] Rittle-Johnson B, Siegler RS, Alibali MW. Developing conceptual understanding and procedural skill in mathematics: An iterative process. J. Educ. Psychol. 2001;93:346-362.

[49] Van de Walle JA, Karp KS, Bay-Williams JM, et al. Elementary and middle school mathematics: Teaching developmentally. Toronto, Canada: Pearson Allyn and Bacon; 2010.

[50] T.C. Millî Eğitim Bakanlığı Talim ve Terbiye Kurulu Başkanlığı. Ortaokul matematik dersi (5, 6, 7 ve 8. sinıflar) öğretim programı [Middle school mathematics curriculum (Grade 5, 6, 7, 8)] [Internet]. 2013 [cited 2016 Apr 27]. Available from: http://ttkb.meb.gov.tr/dosyalar/programlar/ilkogretim/matematik_5-8.rar. 
[51] Cohen J. A Coefficient of Agreement for Nominal Scales. Educ. Psychol. Meas. 1960;20:37-46.

[52] Gwet KL. Handbook of inter-rater reliability: the definitive guide to measuring the extent of agreement among raters. 4th ed. Gaithersburg, USA: Advanced Analytics, LLC; 2014.

[53] Landis JR, Koch GG. The measurement of observer agreement for categorical data. Biometrics. 1977;33:159-174.

[54] Foxman D, Ruddock G. Assessing Mathematics: 3. Concepts and Skills: Line Symmetry and Angle. Math. Sch. 1984;13:9-13.

[55] TIMSS 2011 Released Items with Percent Correct Statistics - Fourth Grade [Internet] [Internet]. 2013 [cited 2016 May 27]. Available from: http://timssandpirls.bc.edu/timss2011/downloads/T11_UG_G4_Released_Items.zip.

[56] Noss R. Children's learning of geometrical concepts through Logo. J. Res. Math. Educ. 1987;343-362.

[57] Outhred L. Left angle or right angel: Children's misconceptions of angle. Res. Math. Educ. Aust. 1987;14:41-47.

[58] Bryant P. Perception and understanding in young children: An experimental approach. New York: Basic Books; 1974.

[59] Bratitsis T, Tatsis K, Amanatidou A. Counting Sounds: An ICT Musical Approach for Teaching the Concept of the Angle in Kindergarten. Rome, Italy: IEEE; 2012. p. 186-190.

[60] Gutiérrez A, Jaime A. Preservice primary teachers' understanding of the concept of altitude of a triangle. J. Math. Teach. Educ. 1999;2:253-275.

[61] Kablan Z, Baran T, Hazer Ö. İlköğretim matematik 6-8 öğretim programında hedeflenen davranışların bilişsel süreçler açısından incelenmesi [A study of the target behaviors in the math curriculum for sixth to eighth grades in reference to cognitive processes]. Ahi Evran Üniversitesi Kırşehir Eğitim Fakültesi Derg. 2013; 14:347-366.

[62] Ma L. Knowing and teaching elementary mathematics: Teachers' understanding of fundamental mathematics in China and the United States. Mahwah, NJ: Lawrence Erlbaum Associates; 1999.

[63] The American Association for the Advancement of Science. Textbooks with the Potential for Helping Students Learn [Internet]. 2000 [cited 2016 Sep 19]. Available from: http://www.project2061.org/publications/textbook/algebra/summary/QualPot.pdf.

[64] The American Association for the Advancement of Science. Textbooks with Little Potential for Helping Students Learn [Internet]. 2000 [cited 2016 Sep 19]. Available from: http://www.project2061.org/publications/textbook/algebra/summary/QualLitt.pdf. 